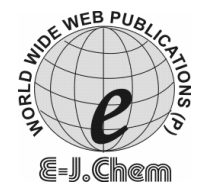

http://www.e-journals.net
ISSN: 0973-4945; CODEN ECJHAO

E-Journal of Chemistry 2009, 6(3), 835-843

\title{
Chelation Ion Exchange Properties of 2, 4-Dihydroxyacetophenone-Biuret -Formaldehyde Terpolymer Resin
}

\author{
SANJIOKUMAR S. RAHANGDALE, \\ ANIL B. ZADE and WASUDEO B. GURNULE* \\ Department of Chemistry, Laxminarayan Institute of Technology, \\ RTM, Nagpur University, Nagpur -440 010, India. \\ *Department of Chemistry, Kamla Nehru College, Nagpur -440 009, India. \\ wbgurnule@yahoo.co.in
}

Received 13 August 2008; Accepted 19 September 2008

\begin{abstract}
The terpolymer resin 2, 4-HABF has been synthesized by the condensation of 2, 4-dihydroxyacetophenone (2, 4-HA) and biuret (B) with formaldehyde (F) in 1:1:2 molar ratios in presence of $2 \mathrm{M}$ hydrochloric acid as catalyst. UV-Visible, IR and proton NMR spectral studies have been carried out to elucidate the structure of the resin. A terpolymer (2, 4-HABF) proved to be a selective chelating ion exchange polymer for certain metals. Chelating ion-exchange properties of this polymer were studied for $\mathrm{Fe}^{3+}, \mathrm{Cu}^{2+}, \mathrm{Ni}^{2+}, \mathrm{Co}^{2+}, \mathrm{Zn}^{2+}, \mathrm{Cd}^{2+}$ and $\mathrm{Pb}^{2+}$ ions. A batch equilibrium method was employed in the study of the selectivity of metal ion uptake involving the measurement of the distribution of a given metal ion between the polymer sample and a solution containing the metal ion. The study was carried out over a wide $\mathrm{pH}$ range and in media of various ionic strengths. The polymer showed highest selectivity for $\mathrm{Fe}^{3+}, \mathrm{Cu}^{2+}$ ions than for $\mathrm{Ni}^{2+}, \mathrm{Co}^{2+}, \mathrm{Zn}^{2+}, \mathrm{Cd}^{2+}$, and $\mathrm{Pb}^{2+}$ ions. Study of distribution ratio as a formation of $\mathrm{pH}$ indicates that the amount of metal ion taken by resin is increases with the increasing $\mathrm{pH}$ of the medium.
\end{abstract}

Keywords: Terpolymer, Resin, Ion-exchange, Distribution ratio.

\section{Introduction}

Ion-exchange may be defined as the reversible exchange of ions between the substrate and surrounding medium. Ion-exchange technique can remove traces of ionic impurities for water / process liquors and gives out a product of ultra pure quality in a simple efficient and techno economically viable manner. Ion-exchangers are widely used in analytical chemistry, hydrometallurgy, antibiotic purification and separation of radio isotopes and find large application in water treatment and pollution control $^{1,2}$. 
Jadhao $\mathrm{M}$ and coworker ${ }^{3}$ have synthesized a terpolymer resin by condensation of 2, 2'dihydroxybiphenyl and formaldehyde in the presence of acid catalyst. They studied chelating ion-exchange properties of this polymer for $\mathrm{Fe}^{3+}, \mathrm{Cu}^{2+}, \mathrm{Ni}^{2+}, \mathrm{Zn}^{2+}, \mathrm{Cd}^{2+}$ and $\mathrm{Pb}^{2+}$ ions. $\mathrm{A}$ batch equilibrium method was employed in the study of the selectivity of metal ion uptake involving the measurement of the distribution of a given metal ion between polymer sample and solution containing metal ions. The study was carried out over a $\mathrm{pH}$ range and reported that the polymer show higher selectivity for $\mathrm{Fe}^{3+}, \mathrm{Cu}^{2+}, \mathrm{Ni}^{2+}$ ions than for $\mathrm{Zn}^{2+}, \mathrm{Cd}^{2+}, \mathrm{Pb}^{2+}$ ions.

Sykora and Dubsky ${ }^{4}$ have prepared a selective cation exchange polymer by reacting 2 , 4dihydroxyacetophenone and anthranilic acid with formaldehyde in alkaline media. They used the polymer for the separation of $\mathrm{Cu}^{2+}$ in weak alkaline media at $\mathrm{pH} 4$. Copolymers have also been synthesized by condensation of a mixture of phenol or hydroxybenzoic acid, various amine and formaldehyde $\mathrm{e}^{5-8}$. Their ion exchange properties and semiconducting properties have been studied. However, a literature survey revealed that no terpolymers have been synthesized from 2, 4dihydroxyacetophenone, biuret and formaldehyde. Therefore, we have carried out synthesis and characterization of these terpolymer and results of our studies are reported in the present article.

The basic requirements that are essential for any polymeric material to be useful as ionexchange resins are as follow:

(a) It must be sufficiently hydrophilic to permit diffusion of ions through the structure at a finite and usable rate.

(b) It must contain sufficient number of accessible ion exchangeable groups which do not undergo degradation during use, and

(c) The swollen material must be denser than water.

The commercially available ion exchange resins are given below.

\begin{tabular}{llcc}
\hline Trade name & Functional group & Polymer matrix & Capacity, meq. $\mathrm{g}^{-1}$ \\
\hline Dowex-1 & $-\mathrm{N}^{+}\left(\mathrm{CH}_{3}\right)_{3} \mathrm{Cl}^{-}$ & $\mathrm{PS}$ & 3.5 \\
Amberlite IRA-45 & $-\mathrm{NR}_{2},-\mathrm{NHR},-\mathrm{NH}_{2}$ & $\mathrm{PS}$ & 5.6 \\
Dowex-3 & $-\mathrm{NR}_{3},-\mathrm{NHR},-\mathrm{NH}_{2}$ & PS & 5.8 \\
Allassian AWB-3 & $-\mathrm{NR}_{2},-\mathrm{N}^{+} \mathrm{R}_{3}$ & Epoxy-Amine & 8.2 \\
Amberlite IR-120 & $-\mathrm{C}_{6} \mathrm{H}_{4} \mathrm{SO}_{3} \mathrm{H}$ & PS & $5.0-5.2$ \\
Duolite C-3 & $-\mathrm{CH}_{2} \mathrm{SO}_{3} \mathrm{H}$ & Phenolic & $2.8-3.0$ \\
Amberlite IRC-50 & $-\mathrm{COOH}$ & Methacrylic & 9.5 \\
Duolite ES-63 & $-\mathrm{OP}(\mathrm{O})(\mathrm{OH})_{2}$ & PS & 6.6 \\
Zeocarb-226 & $-\mathrm{COOH}$ & Acrylic & 10.0 \\
\hline
\end{tabular}

\section{Experimental}

The chemicals 2, 4-dihydroxyacetophenone, biuret and formaldehyde (37\%) used are of analytical grade and chemically pure which is purchased from Merck, India. Solvents like $N, N$ '-dimethyl formamide and dimethylsulphoxide were used after distillation.

\section{Synthesis of 2, 4-HABF terpolymer resin}

The 2, 4-HABF-I terpolymer was prepared by condensing 2, 4-dihydroxyacetophenone $(1.521 \mathrm{~g}, 0.01 \mathrm{~mol})$ and biuret $(1.3 \mathrm{~g}, 0.01 \mathrm{~mol})$ with formaldehyde $(7.5 \mathrm{~mL}, 0.02 \mathrm{~mol})$ in the presence of $2 \mathrm{M} \mathrm{HCl}$ as a catalyst at $126 \pm 2{ }^{0} \mathrm{C}$ in an oil bath ${ }^{9-13}$ for $4 \mathrm{~h}$. The cream colored solid product was washed with hot water and ether to remove unreacted starting materials and acid monomers. The properly washed resin was dried, powdered and then extracted with diethyl ether and then with petroleum ether to remove 2, 4- dihydroxyacetophenoneformaldehyde copolymer which might be present along with the 2, 4 -HABF-I 
terpolymer. It was further purified by dissolving in $10 \% \mathrm{NaOH}$ and then filtered. The terpolymer was then reprecipitated by drop wise addition of $1: 1(\mathrm{v} / \mathrm{v})$ conc. $\mathrm{HCl} /$ water with constant stirring and filtered. The process was repeated thrice. The resulting polymer sample was washed with boiling water and dried in a vacuum at room temperature. The purified terpolymer wash finely ground to pass through 300 mesh size sieve and kept in a vacuum over silica gel. The yield of the terpolymer was found to be about $80 \%$.

\section{Apparatus and procedure}

The terpolymer resins were subject to micro analysis for carbon, hydrogen and nitrogen on Elemental Vario EL III Carlo Erba 1108 Elemental Analyzers at Sophisticated Analytical Instrumentation Facility, Punjab University, Chandigarh. The number average molecular weights $(\overline{M n})$ were determined by conductometric titration in DMF using ethanolic $\mathrm{KOH}$ as the titrant. The molecular weight $(\overline{M n})$ of the terpolymer resin was determined by nonaqueous conductometric titration in DMF against ethanolic $\mathrm{KOH}$ by using $25 \mathrm{mg}$ of sample. Electronic absorption spectra of the terpolymers in DMSO were recorded on Perkin-Elmer Lambda 15 spectrophotometer. Infrared spectra of 2, 4-HABF terpolymers were recorded on Perkin-Elmer 983 spectrophotometer in KBr pallets in the wave number region of $4000-400 \mathrm{~cm}^{-1}$ at SAIF Punjab University, Chandigarh. ${ }^{1} \mathrm{H}-\mathrm{NMR}$ spectra were recorded on Bruker Advance-II $400 \mathrm{MHz}$ proton NMR spectrometer DMSO- $\mathrm{d}_{6}$ was used as a solvents at Sophisticated Analytical Instrumentation Facility, Punjab University, Chandigarh.

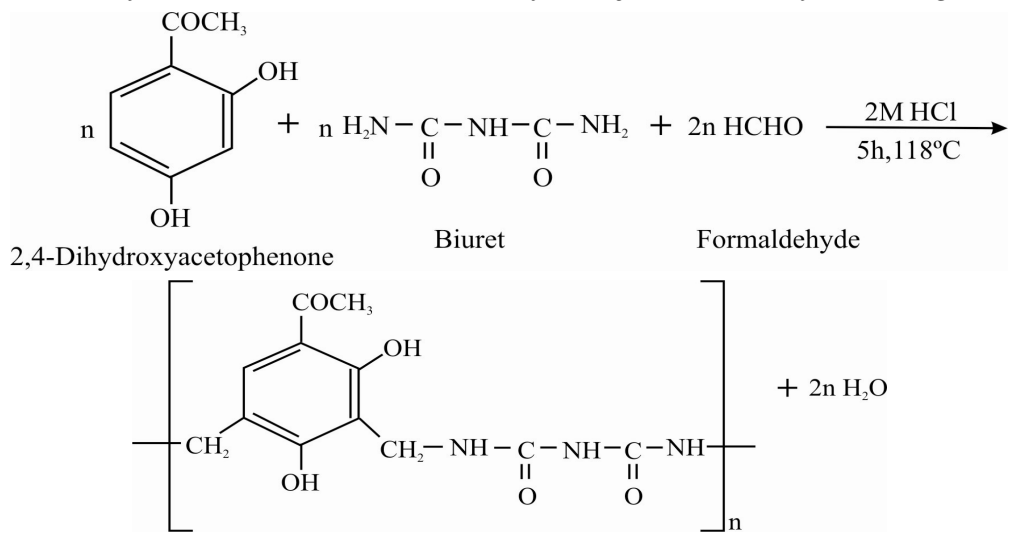

Scheme 1. Reaction and suggested structure of representative 2, 4-HABF-I terpolymer resin.

\section{Ion-exchange properties}

The ion-exchange properties of the 2, 4-HABF terpolymer resins were determined by the batch equilibrium method ${ }^{14}$. The ion-exchange properties of all the four resins have been studied. However, only the data for the 2, 4-HABF-I terpolymer resins have been presented in this report.

Determination of metal uptake in the presence of various electrolytes and different concentrations

The terpolymer sample $(25 \mathrm{mg})$ was suspended in an electrolyte solution $(25 \mathrm{~mL})$ of known concentration. The $\mathrm{pH}$ of suspension was adjusted to the required value by using either $0.1 \mathrm{M}$ $\mathrm{HNO}_{3}$ or $0.1 \mathrm{M} \mathrm{NaOH}$. The suspension was stirred for a period of $24 \mathrm{~h}$ at $25{ }^{\circ} \mathrm{C}$. To this suspension $2 \mathrm{~mL}$ of a $0.1 \mathrm{M}$ solution of the metal ion was added and the $\mathrm{pH}$ was adjusted to the required value. The mixture was again stirred at $25{ }^{0} \mathrm{C}$ for $24 \mathrm{~h}$ and filtered ${ }^{11,12}$. The terpolymer was washed and the filtrate and washings were combined and estimated for the 
metal ion content by titration against standard ethylene diamine tetraacetic acid. A blank experiment was also carried out in the same manner without adding the polymer sample. The blank was again estimated for the metal ion content. The amount of metal ion taken up by the polymer in the presence of the given electrolyte of known concentrations results from the difference between the blank reading and the reading in the actual experiment. The experiment was repeated in the presence of several electrolytes. The results with seven different metal ions are reported in Table 1.

Table 1. Evaluation of the effect of different electrolytes on the uptake of several metal ions ${ }^{\mathrm{a}}$.

\begin{tabular}{|c|c|c|c|c|c|c|}
\hline \multirow{2}{*}{$\begin{array}{c}\text { Metal } \\
\text { ion }\end{array}$} & \multirow{2}{*}{$\begin{array}{c}\text { Electrolyte } \\
\mathrm{mol} \mathrm{l}^{-1}\end{array}$} & \multirow[t]{2}{*}{$\mathrm{pH}$} & \multicolumn{4}{|c|}{ Weight of metal ion (mg) taken up in the presence of } \\
\hline & & & $\mathrm{NaNO}_{3}$ & $\mathrm{NaCl}$ & $\mathrm{NaClO}_{4}$ & $\mathrm{Na}_{2} \mathrm{SO}_{4}$ \\
\hline \multirow[t]{5}{*}{$\mathrm{Zn}^{2+}$} & 0.01 & 5.5 & 2.72 & 4.03 & 3.62 & 2.59 \\
\hline & 0.05 & & 2.61 & 3.72 & 3.29 & 2.21 \\
\hline & 0.10 & & 2.31 & 1.91 & 2.84 & 2.02 \\
\hline & 0.50 & & 2.02 & 1.62 & 2.10 & 1.81 \\
\hline & 1.00 & & 1.62 & 1.41 & 1.82 & 1.79 \\
\hline \multirow[t]{5}{*}{$\mathrm{Cd}^{2+}$} & 0.01 & 5.5 & 2.60 & 2.91 & 2.62 & 2.91 \\
\hline & 0.05 & & 2.41 & 2.69 & 2.31 & 2.52 \\
\hline & 0.10 & & 2.39 & 2.42 & 2.10 & 2.11 \\
\hline & 0.50 & & 1.91 & 2.10 & 1.69 & 1.61 \\
\hline & 1.00 & & 1.60 & 1.77 & 1.55 & 1.49 \\
\hline \multirow[t]{5}{*}{$\mathrm{Pb}^{2+}$} & 0.01 & 5.5 & 2.91 & 2.72 & 2.22 & - \\
\hline & 0.05 & & 2.82 & 2.61 & 2.07 & - \\
\hline & 0.10 & & 2.71 & 2.43 & 1.72 & - \\
\hline & 0.50 & & 2.30 & 2.10 & 1.61 & - \\
\hline & 1.00 & & 1.92 & 1.87 & 1.42 & - \\
\hline \multirow[t]{5}{*}{$\mathrm{Fe}^{3+}$} & 0.01 & 2.5 & 2.32 & 1.51 & 2.31 & 3.73 \\
\hline & 0.05 & & 2.81 & 2.02 & 3.30 & 2.71 \\
\hline & 0.10 & & 3.12 & 2.82 & 3.51 & 2.62 \\
\hline & 0.50 & & 3.32 & 3.31 & 3.90 & 2.10 \\
\hline & 1.00 & & 3.78 & 4.08 & 4.22 & 1.57 \\
\hline \multirow[t]{5}{*}{$\mathrm{Cu}^{2+}$} & 0.01 & 5.0 & 2.02 & 2.42 & 2.92 & 4.62 \\
\hline & 0.05 & & 2.71 & 3.31 & 3.42 & 3.91 \\
\hline & 0.10 & & 3.32 & 3.91 & 3.81 & 3.15 \\
\hline & 0.50 & & 3.43 & 4.52 & 4.31 & 2.30 \\
\hline & 1.00 & & 4.62 & 4.71 & 5.71 & 1.41 \\
\hline \multirow[t]{5}{*}{$\mathrm{Ni}^{2+}$} & 0.01 & 5.5 & 2.31 & 2.40 & 3.21 & 4.15 \\
\hline & 0.05 & & 3.20 & 2.92 & 3.42 & 3.61 \\
\hline & 0.10 & & 3.91 & 3.71 & 3.71 & 2.81 \\
\hline & 0.50 & & 4.69 & 4.21 & 3.89 & 2.15 \\
\hline & 1.00 & & 5.82 & 4.82 & 4.75 & 1.51 \\
\hline \multirow[t]{5}{*}{$\mathrm{Co}^{2+}$} & 0.01 & 5.5 & 2.74 & 3.11 & 3.10 & 3.05 \\
\hline & 0.05 & & 2.39 & 2.40 & 2.61 & 2.50 \\
\hline & 0.10 & & 2.19 & 2.31 & 2.31 & 2.21 \\
\hline & 0.50 & & 1.18 & 2.15 & 2.10 & 1.72 \\
\hline & 1.00 & & 1.01 & 1.75 & 1.60 & 1.51 \\
\hline
\end{tabular}

$\mathrm{Mt}\left(\mathrm{NO}_{3}\right)_{2}=0.1 \mathrm{~mol} \mathrm{l} \mathrm{l}^{-1}$; volume $=2 \mathrm{~mL}$; volume of electrolyte solution $=25 \mathrm{~mL}$, weight of resin $=25 \mathrm{mg}$; time $=24 \mathrm{~h}$; room temperature. 


\section{Evaluation of the rate of metal uptake}

In order to estimate the time required to reach the state of equilibrium under the given experimental conditions, a series of experiments of the type described above were carried out, in which the metal ion up taken by the chelating resins was estimated from time to time at $25{ }^{\circ} \mathrm{C}$ (in presence of $25 \mathrm{~mL}$ of $1 \mathrm{M} \mathrm{NaNO}_{3}$ solution). It was assumed that under the given conditions, the state of equilibrium was established within $24 \mathrm{~h}$. The rate of metal uptake is expressed as percentage of the amount of metal ions taken up after certain time related to that in the state of equilibrium (Table 2).

Table 2. Composition of the rates of metal (M) ion uptake ${ }^{\mathrm{a}}$.

\begin{tabular}{ccccccccc}
\hline Metal ion & $\mathrm{pH}$ & \multicolumn{7}{c}{ Percentage of metal ion uptake ${ }^{\mathrm{b}}$ at different times, $\mathrm{h}$} \\
\cline { 3 - 9 } & & 1 & 2 & 3 & 4 & 5 & 6 & 7 \\
\hline $\mathrm{Zn}^{2+}$ & 5.5 & 47 & 61 & 70 & 86 & 97 & - & - \\
$\mathrm{Cd}^{2+}$ & 5.5 & 22 & 45 & 62 & 65 & 82 & 92 & - \\
$\mathrm{Pb}^{2+}$ & 5.5 & 29 & 42 & 58 & 64 & 82 & 92 & - \\
$\mathrm{Fe}^{3+}$ & 2.5 & 78 & 93 & 98 & - & - & - & - \\
$\mathrm{Cu}^{2+}$ & 5.0 & 56 & 67 & 79 & 94 & 97 & - & - \\
$\mathrm{Ni}^{2+}$ & 5.5 & 49 & 63 & 78 & 92 & 97 & - & - \\
$\mathrm{Co}^{2+}$ & 5.5 & 45 & 62 & 76 & 92 & 94 & - & - \\
\hline
\end{tabular}

${ }^{a} \mathrm{Mt}\left(\mathrm{NO}_{3}\right)_{2}=0.1 \mathrm{~mol} \mathrm{l}^{-1} ;$ volume $=2 \mathrm{~mL} ; \mathrm{NaNO}_{3}=1 \mathrm{~mol} \mathrm{l} \mathrm{l}^{-1}$ volume $=25 \mathrm{~mL} ;$ room temperature.

b Amount of metal ion absorbed $\times 100$

$\overline{\text { Amount of metal ion absorbed at equilibrium }}$

\section{Evaluation of the distribution of the metal ions at different $\mathrm{pH}$}

The distribution of each one of the seven metal ions i.e. $\mathrm{Fe}^{3+}, \mathrm{Cu}^{2+}, \mathrm{Co}^{2+}, \mathrm{Zn}^{2+} \mathrm{Cd}^{+2}, \mathrm{~Pb}^{+2}$ and $\mathrm{Ni}^{2+}$ between the polymer phase and the aqueous phase was estimated at $25{ }^{\circ} \mathrm{C}$ and in the presence of a $1 \mathrm{M} \mathrm{NaNO}_{3}$ solution. The experiments were carried out as described above at different $\mathrm{pH}$ values. The results are presented in Table 3 . The distribution ratio ' $\mathrm{D}$ ' is defined by the following relationship: $\mathrm{D}=$ Weight $(\mathrm{mg})$ of metal ions taken up by $1 \mathrm{~g}$ of terpolymer / weight (mg) of metal ions present in $1 \mathrm{~mL}$ of solution.

Table 3 . Distribution ratio $\mathrm{D}^{\mathrm{a}}$ of different metal ions as a function of the $\mathrm{pH}^{\mathrm{b}}$.

\begin{tabular}{|c|c|c|c|c|c|c|c|c|c|c|}
\hline \multirow{2}{*}{$\begin{array}{c}\text { Metal } \\
\text { ion }\end{array}$} & \multicolumn{10}{|c|}{ Distribution ratio of the metal ion at different $\mathrm{pH}$} \\
\hline & 1.5 & 1.75 & 2.0 & 2.5 & 3.0 & 3.5 & 4.0 & 5.0 & 6.0 & 6.5 \\
\hline $\mathrm{Zn}^{2+}$ & - & - & - & 41.2 & 62.1 & 81.1 & 125.1 & 334.1 & 475.2 & 482.1 \\
\hline $\mathrm{Cd}^{2+}$ & - & - & - & - & 36.2 & 48.2 & 61.2 & 72.1 & 422.1 & 523.6 \\
\hline $\mathrm{Pb}^{2+}$ & - & - & - & 38.1 & 57.2 & 73.5 & 119.2 & 325.2 & 428.2 & 458.1 \\
\hline $\mathrm{Fe}^{3+}$ & 33.2 & 205.1 & 401.3 & 523.2 & - & - & - & - & - & - \\
\hline $\mathrm{Cu}^{2+}$ & - & - & - & 68.2 & 124.2 & 293.2 & 573.2 & 1424.1 & 1707.2 & 1912.2 \\
\hline $\mathrm{Ni}^{2+}$ & - & - & - & 53.2 & 105.2 & 254.2 & 563.2 & 654.2 & 1325.2 & 1424.21 \\
\hline $\mathrm{Co}^{2+}$ & - & - & - & 42.3 & 68.2 & 124.3 & 342.5 & 391.2 & 474.1 & 504.2 \\
\hline \multicolumn{11}{|c|}{${ }^{\mathrm{a}} \mathrm{D}=\frac{\text { Amount of metal ion absorbed } \times 100}{\text { Amount of metal in the solution }} \times \frac{\text { volume of solution }(\mathrm{mL})}{\text { weight of re } \sin (\mathrm{g})}$} \\
\hline
\end{tabular}




\section{Results and Discussion}

The newly synthesized purified 2, 4-HABF resin was found to be cream in colour and soluble in DMF, DMSO, THF and conc. $\mathrm{H}_{2} \mathrm{SO}_{4}$. Analytical data for $\mathrm{C}_{12} \mathrm{H}_{13} \mathrm{~N}_{3} \mathrm{O}_{5}$ as per numerical calculations and experimental evidence are mentioned below respectively. Theoretically calculated $\mathrm{C}=51.61 \%, \mathrm{H}=4.65 \%$ and $\mathrm{N}=15.65 \%$. Experimentally found $\mathrm{C}=52.12 \%, \mathrm{H}=4.12 \%$ and $\mathrm{N}=15.58 \%$. Decomposition temperature of the polymer was found to be above $360{ }^{\circ} \mathrm{C}$.

The molecular weight $(\overline{M n})$ of the terpolymer resin was determined by non-aqueous conductometric titration in DMF against ethanolic $\mathrm{KOH}$ by using $50 \mathrm{mg}$ of sample. A plot of the specific conductance against the milliequivalents of potassium hydroxide required for neutralization of $100 \mathrm{~g}$ of terpolymer was made. Inspection of such a plot revealed that there were many breaks in the plot. From this plot the first break at 392 milliequivalent of base and the last break at 1456 milliequivalent of base were noted. The calculation of $\overline{\mathrm{Mn}}$ by this method is based on the following consideration ${ }^{5,12}$, (1) the first break corresponds to neutralization of the more acidic phenolic hydroxy group of all the repeating units; and (2) the last break in the plot beyond which a continuous increase is observed represents the stage at which phenolic hydroxy group of all the repeating units are neutralized. On the basis of the average degree of polymerization, $\overline{\mathrm{DP}}$ is given by the following relation, is found to be 3.71. On the basis of the average degree of polymerization, $\overline{D P}$ is given by the following relation: $\overline{\mathrm{DP}}=$ (Total meq. of base required for complete neutralization) / (meq. Of base required for smallest interval). The number average molecular weight $(\overline{\mathrm{Mn}})$ is 1035 as obtained by multiplying the $\overline{\mathrm{DP}}$ by the formula weight of the repeating unit ${ }^{17,18}$.

The UV-Visible spectra of all the 2, 4-HABF terpolymer samples in pure DMF were recorded in the region 190-700 $\mathrm{nm}$ at a scanning rate of $100 \mathrm{~nm} \mathrm{~min}^{-1}$ and at a chart speed of 5 $\mathrm{cm} \mathrm{min}^{-1}$. The perusal of the UV-Visible spectra of terpolymers showed almost similar nature. The spectra of these terpolymers exhibit two absorption maxima in the region $280 \mathrm{~nm}$ and 304 $\mathrm{nm}$. These observed positions of the absorption bands indicate the presence of carbonyl group (ketonic) having a carbon-oxygen double bond which is in conjugation with the aromatic nucleus. The appearance of former band (more intense) can be accounted for $\Pi \rightarrow \Pi^{*}$ transition while the later bond (less intense) may be due to $n \rightarrow \Pi^{*}$ electronic transition. The shift from the basic value (viz. $240 \mathrm{~nm}$ and $320 \mathrm{~nm}$ respectively) may be due to conjugation effect, and presence of phenolic hydroxy group (auxochromes) is responsible for hyperchromic effect i.e. $\mathcal{E}_{\max }$ higher values ${ }^{15-17}$. The $\mathcal{E}_{\max }$ value gradually increases in the order: 2 , 4-HABF-I $<2$, 4HABF-II $<2$, 4-HABF-III $<2$, 4-HABF-IV. This increasing order of $\varepsilon_{\max }$ values may be due to introduction of more and more chromophores (carbonyl group) and auxochromes (phenolic$\mathrm{OH}$ groups) in the repeat unit of the terpolymer resins ${ }^{11,18}$. This observation is in good agreement with the proposed most probable structures of these terpolymer resins.

From the IR spectral studies it has been revealed that all the 2, 4-HABF terpolymer give rise to nearly similar pattern of spectra. A broad band appearing in the region 3415$3361 \mathrm{~cm}^{-1}$ to the stretching vibration of phenolic -OH group ${ }^{19,30,31}$ The sharp band displayed at $1627 \mathrm{~cm}^{-1}$ may be on account of the stretching vibrations of carbonyl group $\left(>\mathrm{C}=\mathrm{O}\right.$ ) of biuret moiety ${ }^{17,20}$ Presence of $>\mathrm{NH}$ has been indicated by the medium band at $2365-2363 \mathrm{~cm}^{-1}$ which is merged with broad intense peak due to hydroxyl group ${ }^{18,20}$ The spectra show bands at 800.2-800,1373-1372, 1438-1432 $\mathrm{cm}^{-1}$ which may be ascribed to methylene groups ${ }^{19}$ The sharp peak at $1520-1510 \mathrm{~cm}^{-1}$ may be due to breathing modes of aromatic skeletal ring. 1, 2, 3, 4, 5- penta substitution are indicated by the peaks at 994$990,1094-1090,1198-1189,1283-1279$ and $1373-1330 \mathrm{~cm}^{-1} \cdot{ }^{20,21}$ 
The NMR spectra of all four terpolymers were scanned in DMSO- $\mathrm{d}_{6}$. From the spectra it is reveal that all 2, 4-HABF terpolymers gave rise to different patterns of ${ }^{1} \mathrm{H}$ NMR spectra, since each of the 2, 4-HABF terpolymer possesses sets of proton having different electronic environment.

Except for 2, 4-HABF-I, the remaining three terpolymers viz. 2, 4-HABF-II, 2, 4HABF-III and 2, 4-HABF-IV exhibit singlet signal in the region $\delta$ 2.3-2.7 ppm which are due to methylene protons of the $\mathrm{Ar}-\mathrm{CH}_{2}-\mathrm{Ar}$ bridges ${ }^{16,17,19}$. The weak multiplate signal (unsymmetrical proton) in the region $\delta$ 7.4-7.7 $\mathrm{ppm}$ are due to aromatic protons. The methylenic proton of the Ar- $\mathrm{CH}_{2}-\mathrm{N}$ moity may be recognized as signal appearing in the region $\delta$ 3.3-3.4 $\mathrm{ppm}^{16,17,19}$. The signal in the region $\delta$ 5.1-5.4 $\mathrm{ppm}$ are attributed to the protons of -NH- bridges. The methyl proton of the Ar- $\mathrm{CO}-\mathrm{CH}_{3}$ moiety may be identified by the intense peak at $\delta$ 4.3-4.5 ppm. The signal in the range of $\delta 8.9-9.0 \mathrm{ppm}$ is attributed to phenolic hydroxy proton. This significant downfield chemical shift of the protons of the phenolic $\mathrm{OH}$ group clearly indicates intramolecular hydrogen bonding of $\mathrm{OH}$ with the carbonyl group present at the adjacent ortho position ${ }^{16,17,19}$.

\section{Effect of electrolytes on metal uptake}

We examined the influence of $\mathrm{ClO}_{4}^{-}, \mathrm{NO}_{3}{ }^{-}, \mathrm{Cl}^{-}$and $\mathrm{SO}_{4}{ }^{2-}$ at various concentrations on the position of the equilibrium of metal-resin interactions. Examination of the data given in Table1 reveals that the amount of $\mathrm{Fe}^{3+}, \mathrm{Cu}^{2+}$ and $\mathrm{Ni}^{2+}$ ions taken up by the 2, 4-HABF terpolymer sample increases with increasing concentrations of $\mathrm{ClO}_{4}^{-}, \mathrm{NO}_{3}^{-}$and $\mathrm{Cl}^{-}$and decreases with increasing concentrations of, $\mathrm{SO}_{4}{ }^{2-}$ whereas the uptake of $\mathrm{Co}^{2+}, \mathrm{Zn}^{2+}, \mathrm{Pb}^{2+}$ and $\mathrm{Cd}^{2+}$ ions by above terpolymer increases with decreasing concentrations of $\mathrm{ClO}_{4}^{-}, \mathrm{NO}_{3}{ }^{-}$, $\mathrm{Cl}^{-}$and $\mathrm{SO}_{4}{ }^{2-}$. This may be explained in terms of the stability constants of the complexes which $\mathrm{Cu}^{2+}, \mathrm{Ni}^{2+}, \mathrm{Co}^{2+}, \mathrm{Cd}^{2+}, \mathrm{Zn}^{2+}, \mathrm{Fe}^{3+}$ and $\mathrm{Pb}^{2+}$ ions form with these anions ${ }^{22}$. $\mathrm{SO}_{4}{ }^{2-}$ might form rather strong complexes with $\mathrm{Fe}^{3+}, \mathrm{Cu}^{2+}$ and $\mathrm{Ni}^{2+}$ ions, while $\mathrm{ClO}_{4}^{-}, \mathrm{NO}_{3}^{-}$and $\mathrm{Cl}^{-}$ might form weak complexes and, therefore, might not be expected to influence the position of the $\mathrm{Fe}^{3+}, \mathrm{Cu}^{2+}$ and $\mathrm{Ni}^{2+}$ chelates equilibrium as much as $\mathrm{SO}_{4}{ }^{2-} . \mathrm{ClO}_{4}{ }^{-}, \mathrm{NO}_{3}{ }^{-}, \mathrm{Cl}^{-}$and $\mathrm{SO}_{4}{ }^{2-}$ might form rather strong chelates with $\mathrm{Co}^{2+}, \mathrm{Zn}^{2+}, \mathrm{Pb}^{2+}$ and $\mathrm{Cd}^{2+}$ and, therefore, might be expected to influence the position of the $\mathrm{Co}^{2+}, \mathrm{Zn}^{2+}, \mathrm{Pb}^{2+}$ and $\mathrm{Cd}^{2+}$ chelates equilibrium. This type of trend has also been observed by other investigators in this field ${ }^{23,24,28,29}$.

\section{Rate of metal uptake}

The rate of metal adsorption was determined to find out the shortest period of time for which equilibrium could be carried out while operating as close to equilibrium conditions as possible. Table 2 shows the dependence of the rates of metal ion uptake on the nature of the metal. $\mathrm{Fe}^{3+}$ ion required almost $3 \mathrm{~h}$ for the establishment of equilibrium, while $\mathrm{Cu}^{2+}, \mathrm{Ni}^{2+}$, $\mathrm{Co}^{2+}$ and $\mathrm{Zn}^{2+}$ ions required about $5 \mathrm{~h}$ for equilibrium. $\mathrm{Cd}^{2+}$ and $\mathrm{Pb}^{2+}$ ions required almost 6 $\mathrm{h}$ for equilibrium. The rate of metal uptake follows the order $\mathrm{Fe}^{3+}>\mathrm{Cu}^{2+}, \mathrm{Ni}^{2+}, \mathrm{Co}^{2+}, \mathrm{Zn}^{2+}>$ $\mathrm{Cd}^{2+}$ and $\mathrm{Pb}^{2+}$.

\section{Distribution ratios of metal ions at different $p H$}

The effect of $\mathrm{pH}$ on the amount of metal ions distributed between two phase can be explained by the results shown in Table 3. The results indicate that the relative amount of metal ions taken up by the terpolymer increases with increasing $\mathrm{pH}$ of the medium. The study was carried out up to a definite $\mathrm{pH}$ value for the particular metal ion to prevent hydrolysis of the metal ions at higher $\mathrm{pH}$. The $\mathrm{Fe}^{3+}$ ion is taken up more selectively than any other metal ions under study. $\mathrm{Zn}^{2+}$ and $\mathrm{Pb}^{2+}$ ions have a low distribution ratio in the range of 
pH 4-6. This could be attributed to the low stability constant, i.e. weak ligand stabilization energy, of the metal complexes ${ }^{25,26}$. The possible order of selectivity of a cation exchange resin for divalent metal ions is ${ }^{27}: \mathrm{Cu}>\mathrm{Ni}>\mathrm{Co}>\mathrm{Zn}>\mathrm{Cd}>\mathrm{Fe}$. In the present study the observed order of distribution ratios of divalent ions was found to be $\mathrm{Cu}^{2+}>\mathrm{Ni}^{2+}>\mathrm{Co}^{2+}>$ $\mathrm{Zn}^{2+}>\mathrm{Pb}^{2+}>\mathrm{Cd}^{2+}$, which well with that reported. The results of this study are helpful in selecting the optimum $\mathrm{pH}$ for the selective uptake of a metal ion from a mixture of different ions. For example, for the separation of $\mathrm{Cu}^{2+}$ and $\mathrm{Fe}^{3+}$ ions the optimum $\mathrm{pH}$ is 2.5 , at which the distribution ratio $\mathrm{D}$ for $\mathrm{Cu}^{2+}$ is 68.2 and that for $\mathrm{Fe}^{3+}$ is 523.2.

In order to asses the potential for separation of metal ions such as $\mathrm{Fe}^{3+}$ from other metal ions the following combinations of metal solutions were prepared: (1) $\mathrm{Fe}^{3+}$ and $\mathrm{Cu}^{2+}$, (2) $\mathrm{Fe}^{3+}$ and $\mathrm{Ni}^{2+}$, (3) $\mathrm{Fe}^{3+}$ and $\mathrm{Co}^{2+}$ and (4) $\mathrm{Fe}^{3+}$ and $\mathrm{Zn}^{2+}$. The solutions for separation were prepared by mixing $1 \mathrm{~mL}$ of $1.0 \mathrm{M}$ solution of $\mathrm{Fe}^{3+}$ with $1 \mathrm{~mL}$ of $1.0 \mathrm{M}$ solution of $\mathrm{Cu}^{2+}$, $\mathrm{Ni}^{2+}, \mathrm{Co}^{2+}$ or $\mathrm{Zn}^{2+}$. Selective uptake of the metal ions was studied by adjusting the optimum $\mathrm{pH}$ of 2.5. The lowering in the distribution ratios of $\mathrm{Fe}^{3+}$ is found to be small and, hence, efficient separation could be achieved. A similar trend has also been observed by earlier investigators $^{32}$.

\section{Conclusions}

- A terpolymer 2, 4-HABF based on the condensation reaction of 2, 4dihydroxyacetophenone and biuret with formaldehyde in the presence of acid catalyst has been prepared.

- 2, 4-HABF is a selective chelating ion exchange polymer for certain metals.

- The terpolymer showed a higher selectivity for $\mathrm{Cu}^{2+}$ and $\mathrm{Fe}^{3+}$ ions than for $\mathrm{Co}^{2+}$ and $\mathrm{Zn}^{2+}$ ions.

\section{Acknowledgement}

The authors are pleased to express their gratitude to the Director, Laxminarayan Institute of Technology, RTM Nagpur University, Nagpur, for providing laboratory facility. Authors are also thankful to the Director, Sophisticated Analytical Instrumentation Facility, Punjab University, Chandigarh for spectral analysis.

\section{References}

1. Helfferich F, Ion Exchange Resins, New York; McGraw Hill, 1962.

2. Kunin R, Ion Exchange Resin, $3^{\text {rd }}$ Ed, New York; Wiley, 1958.

3. Jadhao M M, Paliwal L J and Bhave N S, Appl Polymer Sci., 2008, 109(1), 508-514.

4. Sykora V and Dubsky F, Czech Patent, 1964, 110, 864; Chem Abstr., 1964, 61, 16263c.

5. Gurnule W B, Rahangdale P K, Paliwal L J and Kharat R B, Synth React Inorg MetOrg Chem., 2003, 33, 1187.

6. Joshi R M and Patel M M, J Macromol Sci Chem., 1983, 19, 705.

7. Tarase M V, Zade A B and Gurnule W B, J Appl Polym Sci., 2008, 108(2), 738-746.

8. Rahangdale S S, Zade A B and Gurnule W B, J Appl Polym Sci., 2008, 108(2), 747-756.

9. $\quad$ Singru R N, Zade A B \& Gurnule W B, J Appl Polym Sci., 2008, 109(2), 859-868.

10. Maki T, Ishihara K and Yamamoto H, Tetrahedron, 2007, 10, 1016.

11. Jadhao M, Paliwal L J and Bhave N S, Indian J Chem., 2005, 44, 1110.

12. Gurnule W B, Rahangdale P K, Paliwal L J \& Kharat R B, React Funct Polym., 2003, 55, 255.

13. Gurnule W B, Rahangdale P K, Paliwal L J and Kharat R B, J Applied Polym Sci., 2003, 89(3), 886. 
14. Gurnule W B, Juneja H D, Paliwal L J and Kharat R B, React Funct Polym., 2002, 50, 95.

15. Maron S H and Reznik R B, J Polym Sci., 1969, 2, 309.

16. Dudley H and Fleming I, Spectroscopic Methods in Organic Chemistry; McGrawHill:UK., 1975.

17. Silverstein R M \& Bassler G C, Spectrometric Identification of Organic Compounds, 2nd Ed., (John Wiley: New york) 1967.

18. Dunn G E and McDonald R C, Can J Chem., 1967, 47, 4577.

19. Nakanishi K, Infrared Absorption Spectroscopy Practical, Noldden Day, INC and Nankodo Co Ltd: Tokyo, 1967.

20. Ballemy I J, The IR Spectra of Complex Molecules, Methuen and Wiley, New York, 1956 \& 1958.

21. Pal T K and Kharat R B, Indian J Chem., 1989, 28A, 55-58.

22. Bjerrum J, Schwarzenbach G and Sillen G, Stability Constants of Metal -Ion Complexes, Vol. 1, The Chemical Society, London, 1958.

23. Patel B S and Patel S R, Makromol Chem., 1979, 180, 1159.

24. Manavalan R and Patel M M, Makromo Chem., 1983, 184, 717.

25. Cotton F A and Wilkinson G, Advanced Inorganic Chemistry, $3^{\text {rd }}$ Ed., Wiley, New York, 1972.

26. Davydova S L and Plate N A, Coord Chem Rev., 1975, 16, 195.

27. Irving H and Williams R J, J Chem Soc., 1953, 3207.

28. Savith P and Sathyanarayana D N, J Polym Sci., 2005, 43, 3040.

29. Deshkhun A, Young G and Choi U, React Funct Polym., 2007, 67, 312.

30. Meenakshi S and Vishwanathan N, J Colloid Interface Sci., 2007, 308, 438.

31. Singh B and Sharma N, J Polym Degrade Stab., 2007, 1, 19.

32. Mashram D T, Karia K P and Bhave N S, e-Polymers, 2007, 075. 


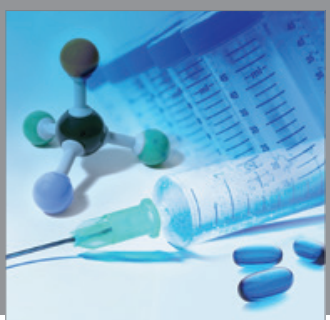

International Journal of

Medicinal Chemistry

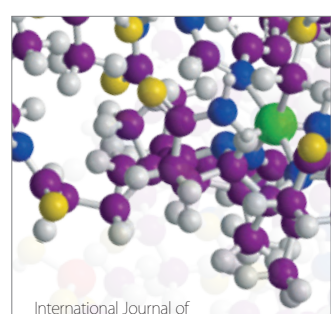

Carbohydrate Chemistry

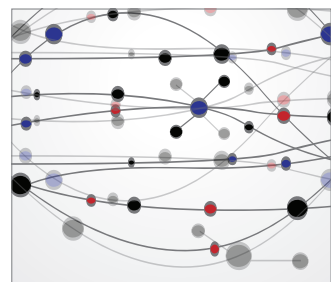

The Scientific World Journal
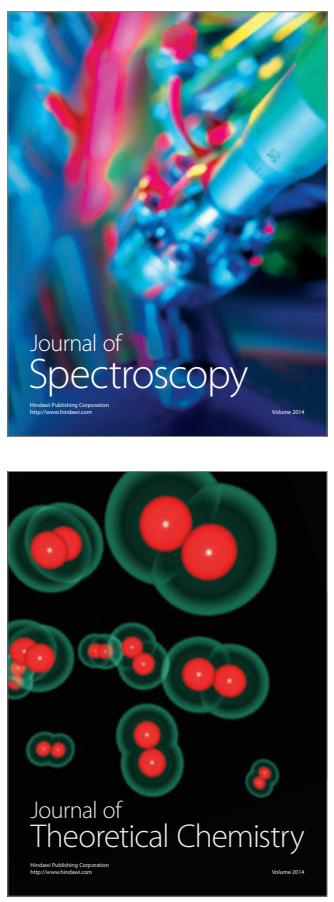
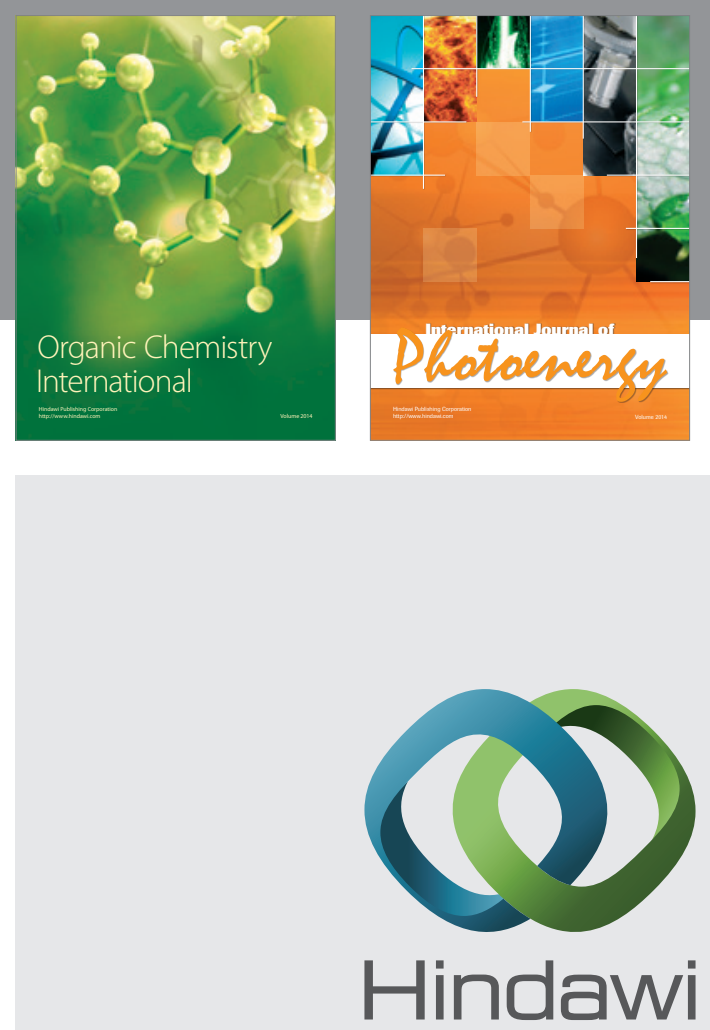

Submit your manuscripts at

http://www.hindawi.com
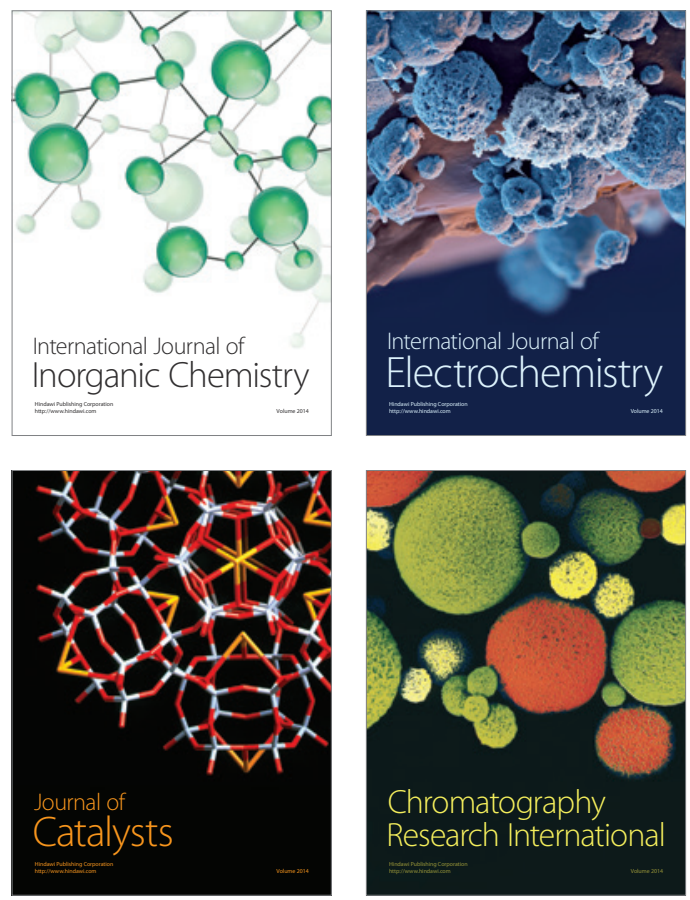
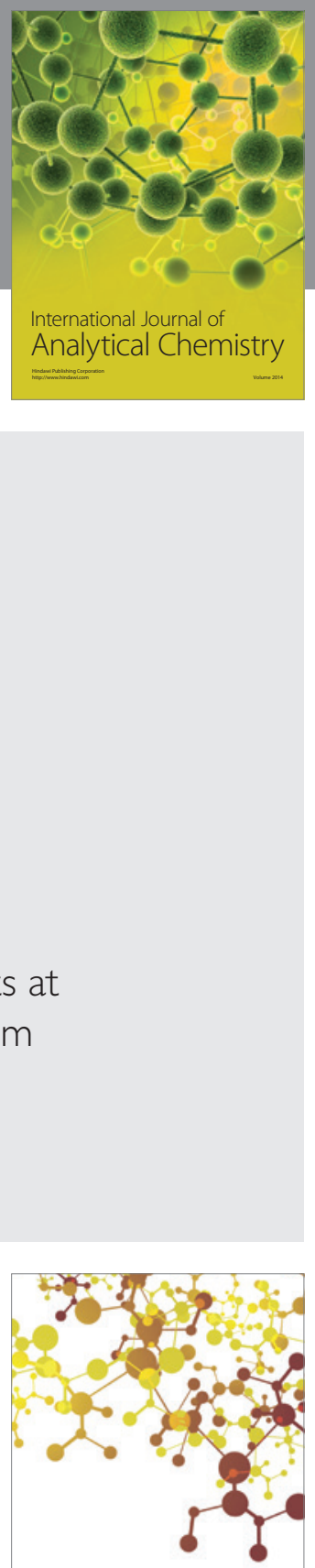

Journal of

Applied Chemistry
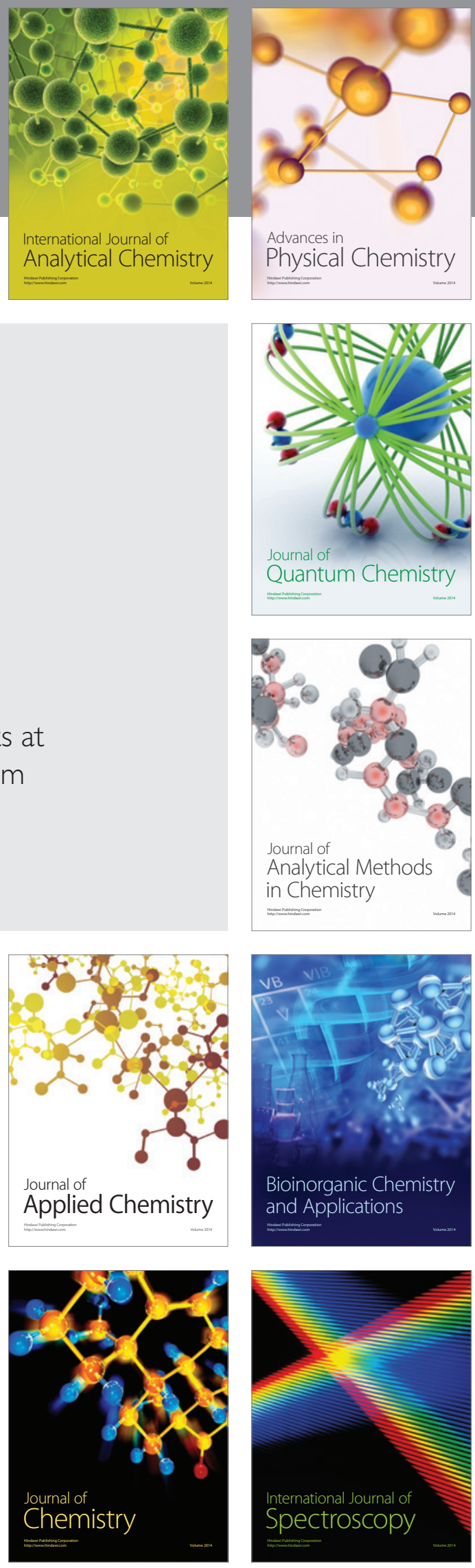